\title{
EVALUATION OF SPECIFIC PROCESS PARAMETERS AND ULTRASONICALLY ACTIVATED INJECTION AFFECTING THE QUALITY OF FILLING IN THIN WALLED PLASTIC PARTS
}

\author{
Andrei Adam, Daniel Stan, Aurel Tulcan \\ Politehnica University Timisoara, Department of Materials and Manufacturing Engineering, Romania \\ e-mail: andreiadam83@yahoo.com
}

\begin{abstract}
The paper presents a set of experiments focused on the study of rheological behavior of a polymer flowing through a narrow section at the forming by injection of thin-walled plastic parts. The paper addresses the use of ultrasonically activated injection for fabrication of polymeric parts with thin wall features. In the experiment, a part with six different geometric features has been created. The design-of-experiments approach is applied to correlate the quality of the parts with the processing parameters. Four processing parameters are investigated using a screening factorial experimentation plan to determine their possible effect on the filling quality of the moulded parts. The experiments have been conducted on a hot runner mould with two nests in which the final (nest) nozzle has been modified to host, as the central element, the ultrasonic horn of a sonic system. It has been found that the ultrasonic activation applied on the active part of the mould does not play an important role as a stand-alone factor but could amplify or strengthen the effect of classical setting parameters (and influence factors) of the process: the melt temperature and injection pressure. Because it is easier to stimulate and to control rheological properties of the melt by setting the intensity of ultrasonic energy and, more important, the effect is forthwith, the paper recommends the runner systems with ultrasonic activation as an alternative for the hot runner with heating elements.
\end{abstract}

Keywords: ultrasonic activation, design-of-experiments, rheological behavior of the polymer, thin-walled plastic parts

\section{Introduction}

Injection moulding is the most common forming method for the manufacturing of plastic parts. With high productivity, it is based on accurate replication of the nest. In the industrial design and manufacturing, it is always a challenge to make a proper compromise between the most desirable shape of parts, tooling cost, their weight and as well as strength and rigidity (Adam et al., 2013). The primary concern is to respect the quality requirements for the moulded parts. Especially for thin-walled parts, difficulties in the process are due to poor rheological capabilities of the melt flowing through thin section (negative of the thin-walled).

Based on the previous research results, for the ultrasonic activation of the extrusion (Stan, 1999; Stan et al., 2000), we supposed that the so called "thermo-pellicular effect" of the sonic activation of the polymer melt under pressure could also be obtained in injection conditions to improve the flow and replication capability of the melt in the above mentioned conditions.

The main approach to identify influential processing parameters in thin-wall injection moulding was by changing one parameter at a time while keeping the others constant, and then observing the effects of that parameter (Wimberger-Friedl, 2000). This approach was inherited from conventional injection moulding. It was useful in drawing basic conclusions about how each parameter affects the filling quality of the moulded part. This approach, however, has two main 
limitations (Eriksson et al., 2008): the first limitation is that it is relatively time consuming when many parameters are being investigated, the second drawback is that it does not take into consideration the effect of the interaction between two or more parameters, which is relevant consideration in a complex process such as ultrasonically activated injection used on thin-walled plastic parts.

In this paper, the design-of-experiments (DOE) approach is introduced into the research domain as a useful alternative to conventional methods. A number of research groups have used a variety of DOE experimentation plans to investigate the relation between processing parameters and part filling quality (Attia et al., 2009). The responses chosen for the experiments included filling quality of micro-sized channels (Mönkkönen et al., 2002), part dimensions (Zhao et al. 2003; Aufiero, 2005; Baltes and Tierean, 2009; Pirskanen et al. 2005; Malloy, 1994) and flow length (Jung et al., 2007).

Results presented in the literature show that different DOE designs yield different outputs. For example, there is disagreement about the importance of holding pressure and injection speed. Furthermore, certain experiments have highlighted interactions between processing parameters which have not been seen in other works. These differences in experimental results may be due to different geometrical shapes as well as polymers and experimental set-ups used in each experiment (Baltes and Tierean, 2009). It would, therefore, seem reasonable to claim that, at present, significant processing parameters in thin wall injection are identified on case-by-case basis and cannot be generalized for all situations.

This paper addresses the effects of ultrasonically activated injection and specific processing parameters on the filling quality for thin walled plastic parts through the design-of-experiments (DOE) approach.

\section{Experimental part}

\subsection{Mould design}

Mould flow simulations have been carried out using the finite element method (FEM) which is one of the best methods to perform various computer and engineering simulations. This method incorporates programs that have become essential parts of modern computer aided design (Bariani et al., 2007).

Generally, using computer aided simulation in plastics technology, consists in assumption of various scenarios with a certain number of injection points with different locations in relation to the 3D configuration of the part to be injected with various injection point lengths and diameters, and determining the correct size of the gate. For parts with thin walls this kind of the engineering approach is very important because the location of the injection point should be achieved as effectively as possible, so as to provide balanced mold filling (Chang, 2007).

For the experiment, a geometric part has been created that has flow channels with thickness (gap, $i$ ) of $0.2 \mathrm{~mm}, 0.3 \mathrm{~mm}, 0.4 \mathrm{~mm}, 0.5 \mathrm{~mm}$ and $0.6 \mathrm{~mm}$ (Fig. 1).

The experiments were done with the following injection parameters:

1. $T_{i n j}=230^{\circ} \mathrm{C}, P_{i n j}=200 \mathrm{MPa}(2000 \mathrm{bar})$,

2. $T_{i n j}=280^{\circ} \mathrm{C}, P_{i n j}=200 \mathrm{MPa}(2000 \mathrm{bar})$.

In the first case, the results show that in the flow channels with smaler gaps the injected material (ABS) does not completely fill the whole volume (Fig. 2). The significance of the colours are: orange shows no problems with the flow rate and red/grey that there will be problems with flow and maybe no complete filling of the cavity.

In the second case, at a higher injection temperature, the results show that the flow channels are completly filled, but for smaller gaps $(i=0,2$ and 0,3$)$, there are still some issues (Fig. 3 ). 


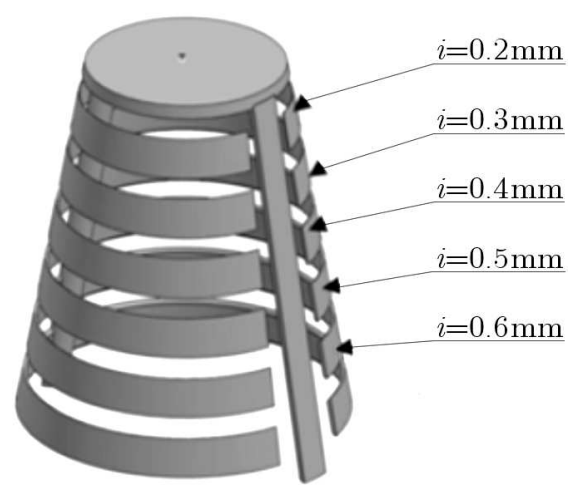

Fig. 1. Proposed geometrical model of the injected part
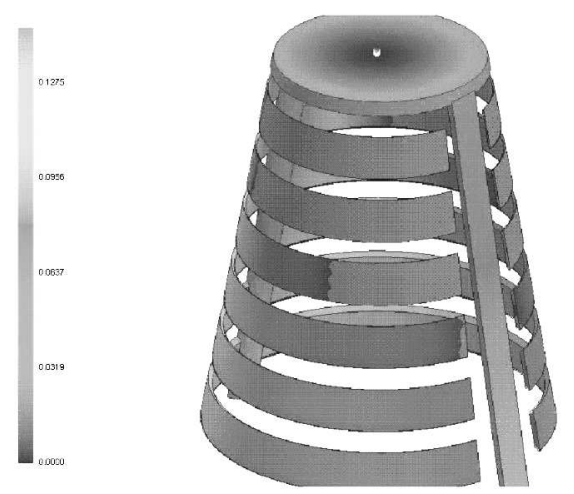

Fig. 2. Flow simulations, first case
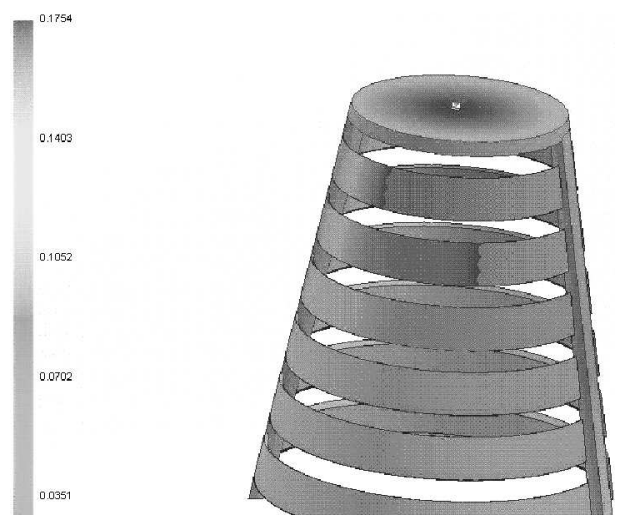

Fig. 3. Flow simulations, second case

\subsection{Factorial experiment}

For the experiment, we have chosen a patented invention (Fig. 4). The patent (Patent No. $118576 \mathrm{~B} / 2003)$ relates to an inventive concept for the design of hot-runner injection molds in which to improve the nests filling and quality of the parts, an ultrasonic converter (ultrasonic transducer (1) + concentrator wave adapter (2)) is placed in the hot block (plate) (3) centered on each final nozzle (4), so that in the proximity of the injection point (gate) (5) a powerful thermo-pellicular effect is created in the molten plastic flowing in contact with the wave adapter and to the top of this (Iclanzan et al., 2008). In order to estimate the effects of ultrasonic activation, the second nest was placed in the mould with a classic (without ultrasonic activation) final injection nozzle. 


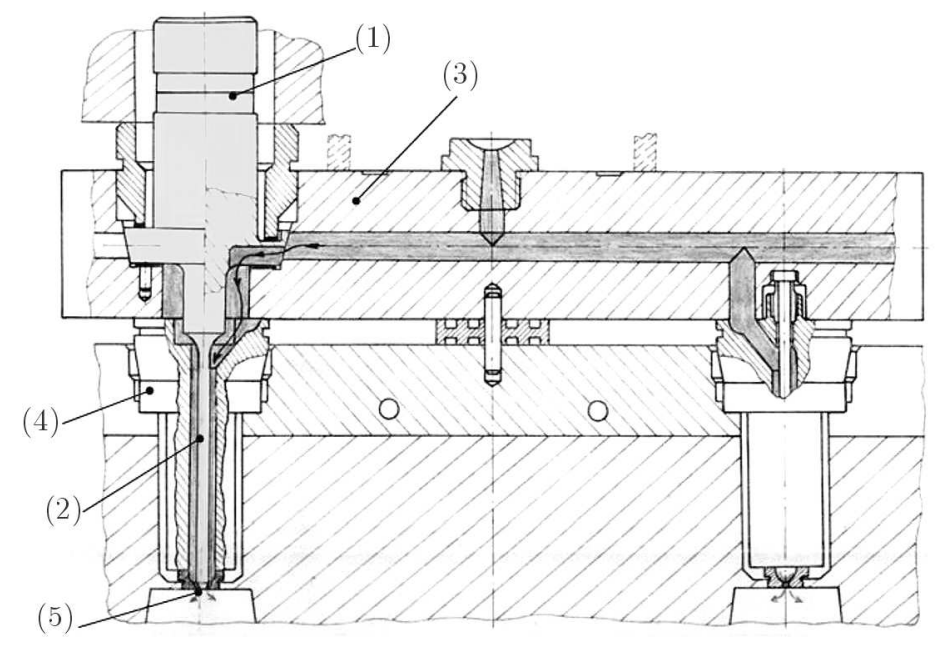

Fig. 4. Ultrasonically activated mould

The material used for the tests was acrylonitrile-butadiene-styrene (ABS) because of its higher injection load resistance and a significant melt flow rate (MFI=35 g/10 min).

The tests were carried out on an injection mould (Fig. 5) that was mounted on the Krauss Maffei KM 200-700 C2 injection machine.

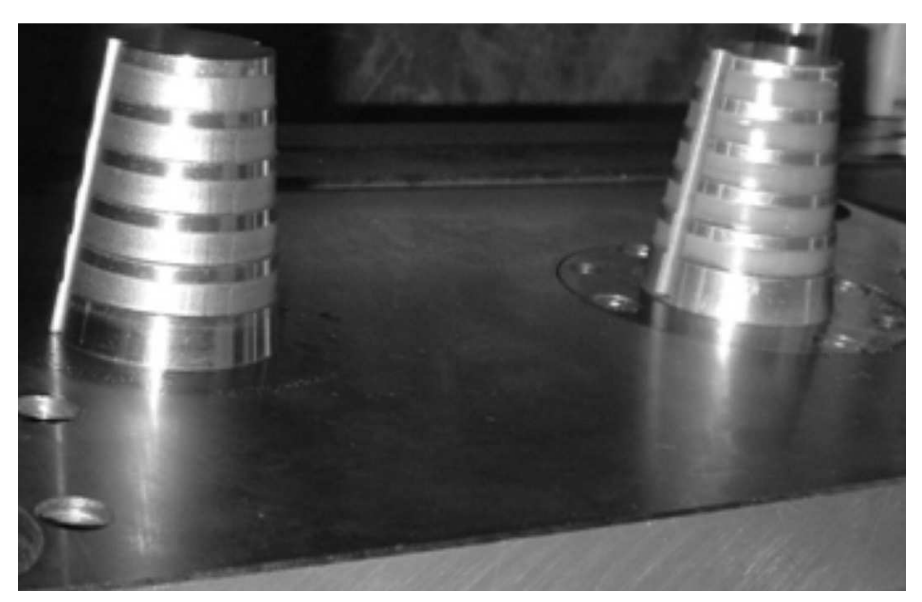

Fig. 5. Cores of the injection mould

The injected parts that were obtained during the experiments (Fig. 6) were measured along the length traveled by the plastic flow through the narrow cavities of the "ribs", as the amount of rheological capability of the melt.

The experimental plan was designed for four influence factors (independent variables), three of them being the classical setting parameters for the control of rheological properties of the melt: pressure, temperature and gap (opening of the free flowing section) plus the fourth factor, ultrasonic activation of the injection (nest) nozzle. The response (dependent) variable considered to be relevant for the assessment of rheological capabilities of the melt was the length of the flow until solidification. The levels of the independent variables are presented in Table 1.

Experimental results obtained with and without ultrasonic activation are presented in Table 2. 

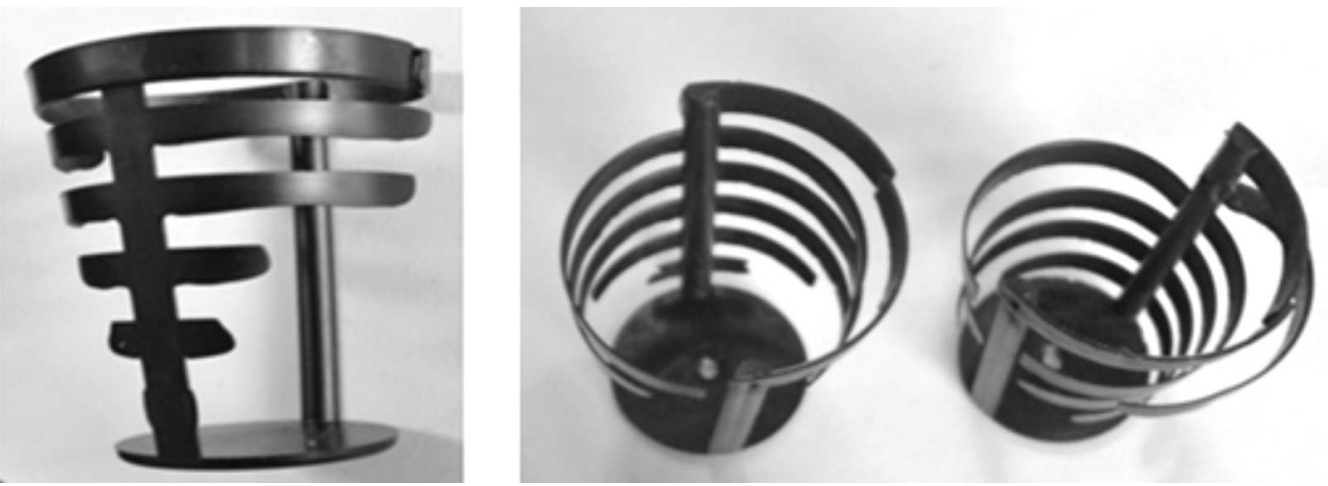

Fig. 6. Parts obtained for different $p-T$ combinations

Table 1. Levels of the independent variables

\begin{tabular}{|c|c|c|c|c|c|c|c|}
\hline \multicolumn{2}{|c|}{$\begin{array}{c}\text { Pressure } \\
\text { [bar] }\end{array}$} & \multicolumn{2}{|c|}{$\begin{array}{c}\text { Temperature } \\
{\left[{ }^{\circ} \mathrm{C}\right]}\end{array}$} & \multicolumn{2}{|c|}{$\begin{array}{l}\text { Gap } \\
{[\mathrm{mm}]}\end{array}$} & \multicolumn{2}{|c|}{$\begin{array}{c}\text { Ultrasonic activation at } \\
\text { maximum amplitude }(U S)\end{array}$} \\
\hline-1 & +1 & -1 & +1 & -1 & +1 & -1 & +1 \\
\hline 1500 & 2000 & 230 & 280 & 0.2 & 0.5 & $\begin{array}{l}\text { without } \\
U S\end{array}$ & $\begin{array}{l}U S \text { of the injection nozzle: } \\
\text { Frequency: } 35 \mathrm{kHz} \\
\text { Power: } 10 \%\left(P_{\text {nom }}=1 \mathrm{~kW}\right)\end{array}$ \\
\hline
\end{tabular}

Table 2. Experimental design results

\begin{tabular}{|c|c|c|c|c|c|}
\hline \multirow{2}{*}{$\begin{array}{c}\text { Exp } \\
\text { ctr. }\end{array}$} & \multicolumn{6}{|c|}{$\begin{array}{c}\text { Independent variables of the experimental design (coded) } \\
\text { Presure } \\
{[\mathrm{bar}]}\end{array}$} & $\begin{array}{c}\text { Temperature } \\
T \\
{\left[{ }^{\circ} \mathrm{C}\right]}\end{array}$ & $\begin{array}{c}\text { Gap } \\
i \\
{[\mathrm{~mm}]}\end{array}$ & $\begin{array}{c}\text { Ultrasoinc } \\
\text { activation } U S \\
{[-1=\mathrm{NO} ;+1=\mathrm{YES}]}\end{array}$ & $\begin{array}{c}\text { Lenght of the } \\
\text { rib } L \\
{[\mathrm{~mm}]}\end{array}$ \\
\hline \hline 1 & +1 & -1 & +1 & +1 & 30 \\
\hline 2 & +1 & +1 & +1 & +1 & 43 \\
\hline 3 & +1 & -1 & -1 & -1 & 2 \\
\hline 4 & -1 & +1 & +1 & -1 & 32 \\
\hline 5 & -1 & -1 & -1 & -1 & 24 \\
\hline 6 & -1 & -1 & +1 & +1 & 5 \\
\hline 7 & -1 & +1 & -1 & -1 & 26 \\
\hline 8 & +1 & -1 & +1 & -1 & 36 \\
\hline 9 & -1 & +1 & +1 & +1 & 21 \\
\hline 10 & -1 & +1 & -1 & +1 & 7 \\
\hline 11 & -1 & -1 & +1 & -1 & 6 \\
\hline 12 & +1 & -1 & -1 & +1 & 10 \\
\hline 13 & -1 & -1 & -1 & +1 & 41 \\
\hline 14 & +1 & +1 & -1 & -1 & 18 \\
\hline 15 & +1 & +1 & +1 & -1 & 0 \\
\hline 16 & +1 & +1 & -1 & +1 & \\
\hline
\end{tabular}

\section{Experimental results}

For the processing of the results, the Statgraphics ${ }^{\mathrm{TM}}$ program has been used. The primary influence factors that are taken into consideration are pressure, temperature and gap. Table 3 shows each of the estimated effects and interactions. Also shown is the standard error of each effect, which measures their sampling error, and that the largest variance inflation factor (V.I.F.) 
equals 1.0. For a perfectly orthogonal design, all factors would be equal to 1. Standard errors are based on the total error with 5 d.f.

Table 3. Estimated effects for the travelled length

\begin{tabular}{|l|c|c|c|}
\hline \multicolumn{1}{|c|}{ Effect } & Estimate & Stnd. error & V.I.F. \\
\hline \hline Average & 19.6875 & 0.232177 & \\
\hline A: Injection pressure & 4.875 & 0.464354 & 1.0 \\
\hline B: Injection temperature & 10.375 & 0.464354 & 1.0 \\
\hline C: Gap & 23.875 & 0.464354 & 1.0 \\
\hline D: Ultrasonic activation & 5.125 & 0.464354 & 1.0 \\
\hline AB & 1.375 & 0.464354 & 1.0 \\
\hline AC & 1.875 & 0.464354 & 1.0 \\
\hline AD & -0.375 & 0.464354 & 1.0 \\
\hline BC & 2.375 & 0.464354 & 1.0 \\
\hline BD & 0.625 & 0.464354 & 1.0 \\
\hline CD & -1.875 & 0.464354 & 1.0 \\
\hline
\end{tabular}

In order to test the statistical significance of the effects, the analysis of variance, called ANOVA has been used. The results obtained are shown in Table 3. The four independent variables are encoded by $\mathrm{A}, \mathrm{B}, \mathrm{C}$ and $\mathrm{D}$, and the interaction by $\mathrm{AB}, \mathrm{AC}, \mathrm{AD}, \mathrm{BC}, \mathrm{BD}$ and $\mathrm{CD}$ which are products of the independent factors.

Table 4. ANOVA chart for the travelled length

\begin{tabular}{|l|c|c|c|c|c|}
\hline \multicolumn{1}{|c|}{ Source } & Sum of squares & D.f. & Mean square & $F$-ratio & $P$-value \\
\hline \hline A: Injection pressure & 95.0625 & 1 & 95.0625 & 110.22 & 0.0001 \\
\hline B: Injection temperature & 430.563 & 1 & 430.563 & 499.20 & 0.0000 \\
\hline C: Gap & 2280.06 & 1 & 2280.06 & 2643.55 & 0.0000 \\
\hline D: Ultrasoinc activation & 105.063 & 1 & 105.063 & 121.81 & 0.0001 \\
\hline AB & 7.5625 & 1 & 7.5625 & 8.77 & 0.0315 \\
\hline AC & 14.0625 & 1 & 14.0625 & 16.30 & 0.0099 \\
\hline AD & 0.5625 & 1 & 0.5625 & 0.65 & 0.4560 \\
\hline BC & 22.5625 & 1 & 22.5625 & 26.16 & 0.0037 \\
\hline BD & 1.5625 & 1 & 1.5625 & 1.81 & 0.2361 \\
\hline CD & 14.0625 & 1 & 14.0625 & 16.30 & 0.0099 \\
\hline Total error & 4.3125 & 5 & 0.8625 & & \\
\hline Total (corr.) & 2975.44 & 15 & & & \\
\hline
\end{tabular}

$R$-squared $=99.8551 \%, R$-squared (adjusted for d.f.) $=99.5652 \%$

standard error of est. $=0.928709$, mean absolute error $=0.445313$

Durbin-Watson statistic $=1.7971(P=0.4020)$

lag 1 residual autocorrelation $=-0.0226449$

The program determines, for each effect individually, the Fisher criteria which compare it with the $F$-distribution table (critical values), and finally establishes the importance of that factor which has a significant influence. In this case, the main factors and other three interactions have $P$-values less than 0.05 , indicating that they are significantly different from zero at the $95.0 \%$ confidence level. The $R$-squared statistic indicates that the model as fitted explains $99.85 \%$ of the variability in the Travelled length. The adjusted $R$-squared statistic, which is more suitable for comparing models with different numbers of independent variables, is $99.56 \%$, which shows that the mathematical modeling of the phenomenon is very good. 
The influence of the travelled lenght can be seen in the Pareto chart (Fig. 7), where the vertical line represented for $P=0.05$ separates the significant factors from the others. The fact that the release is random can also be seen in Fig. 8, where it can be observed that there is no systematic arrangement between the experimentally obtained results and the residual dispersion from the values estimated by the mathematical model.

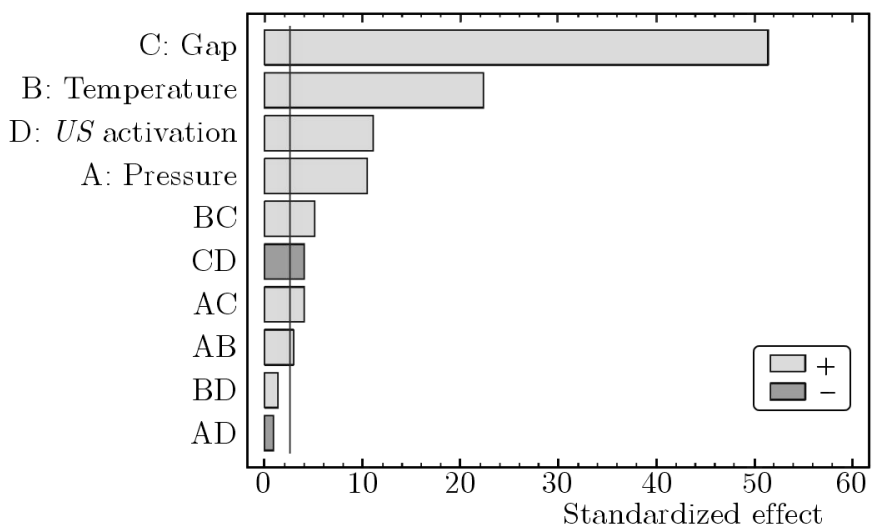

Fig. 7. Pareto chart for the traveled length

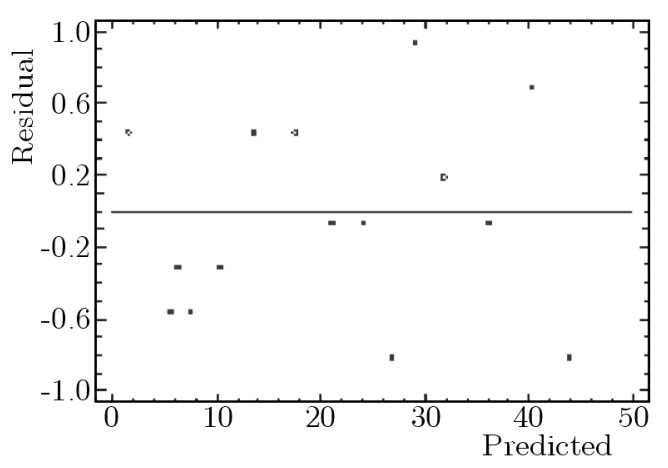

Fig. 8. Diagram of the residual

Based on the regression coefficients associated with the significant factors $P, T, G$, and ultrasonic activation (US), Table 5 , the length travelled by the plastic material a mathematical model could be predicted Mathematical model

$$
\begin{aligned}
& \text { Traveled length }=19.6875+2.4375 P+5.1875 T+11.9375 G+2.5625(U S) \\
& \quad+0.6875 P T+0.9375 P G-0.1875 P(U S)+1.1875 T G+0.3125 T(U S) \\
& \quad-0.9375 G(U S)
\end{aligned}
$$

In Fig. 9, the main effects of the response function, i.e. the length traveled are shown. It is noted that the four determinant factors and their interactions lead to an increase in the value of the travelled lenght by increasing their minimum to maximum.

In the next figures, variation of the estimated response surface (a) and its contours (b) corresponding to the length travelled by the plastic material depending on combinations of the four factors is shown.

\section{Conclusions}

The results of this paper show that for all the analyzed cases, with or without ultrasonic injection, the gap $i$ is the main influence factor. This situation is expected because, as in the scientific literature, the lower limit usually considered for the gap (thinnest wall of the part) is 
Table 5. Estimated regression coefficients for the length travelled by the plastic material

\begin{tabular}{|l|c|}
\hline Coefficient & Estimate \\
\hline \hline Constant & 19.6875 \\
\hline A: Presure & 2.4375 \\
\hline B: Temperature & 5.1875 \\
\hline C: Gap & 11.9375 \\
\hline D: US activation & 2.5625 \\
\hline AB & 0.6875 \\
\hline AC & 0.9375 \\
\hline AD & -0.1875 \\
\hline BC & 1.1875 \\
\hline BD & 0.3125 \\
\hline CD & -0.9375 \\
\hline
\end{tabular}
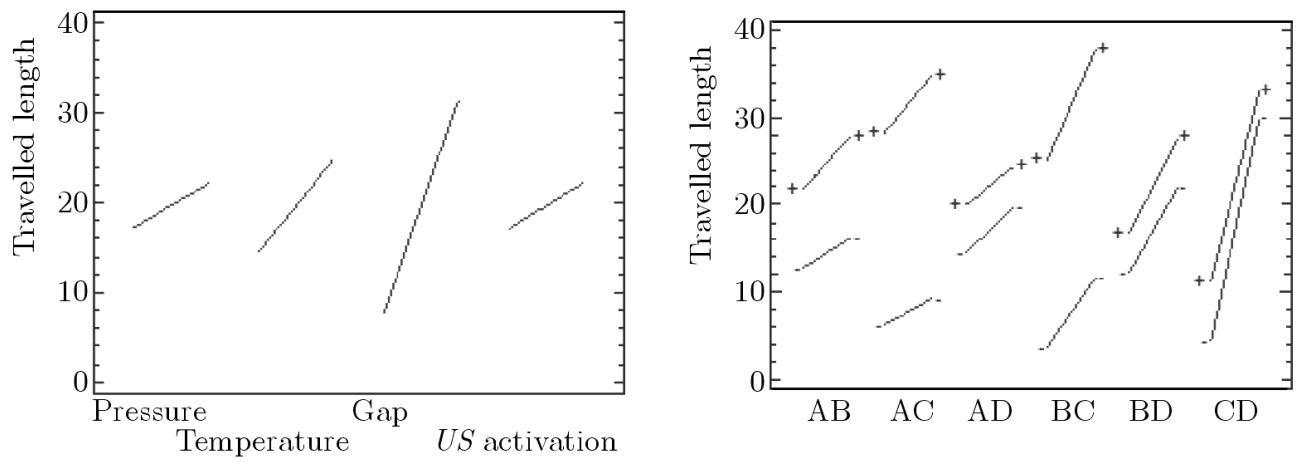

Fig. 9. Main effects on the travelled length
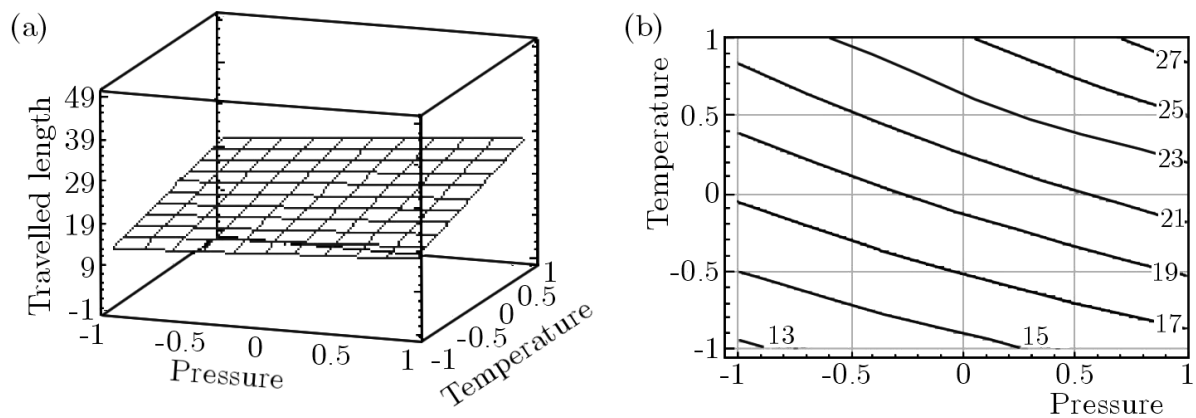

Fig. 10. The influence of pressure and temperature
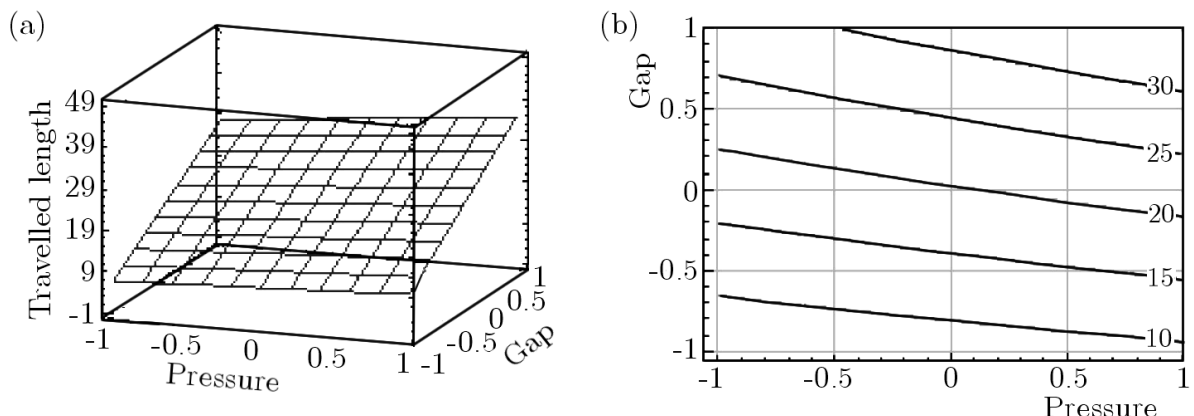

Fig. 11. The influence of pressure and gap 

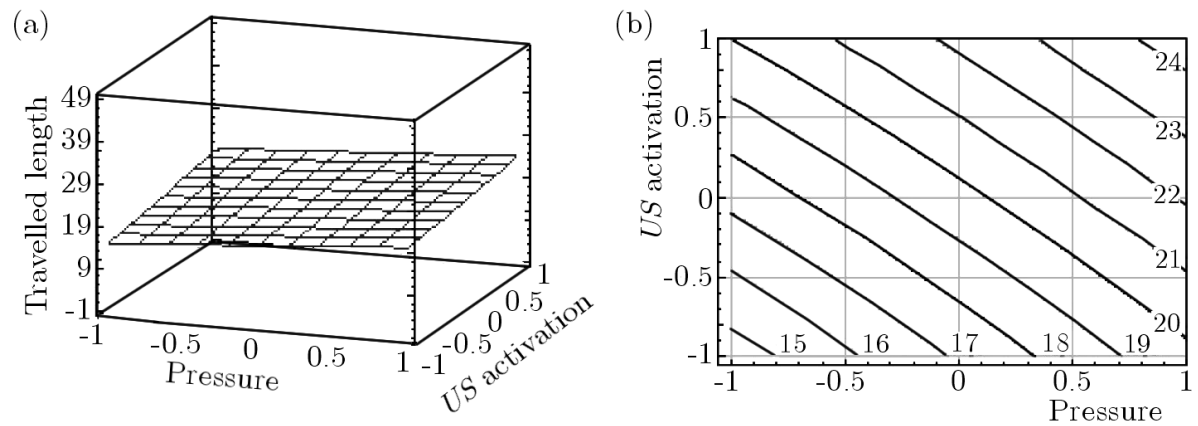

Fig. 12. The influence of pressure and $U S$ activation
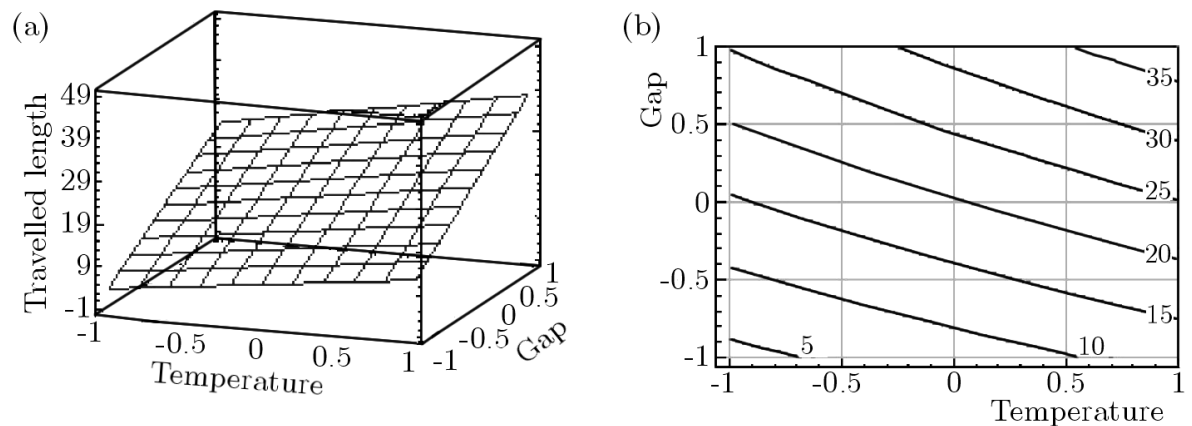

Fig. 13. The influence of temperature and gap
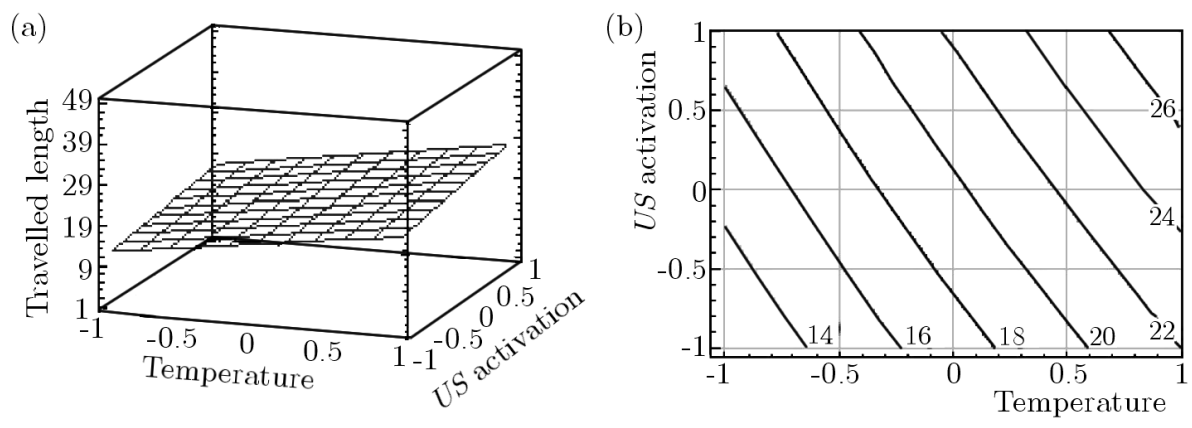

Fig. 14. The influence of temperature and $U S$ activation
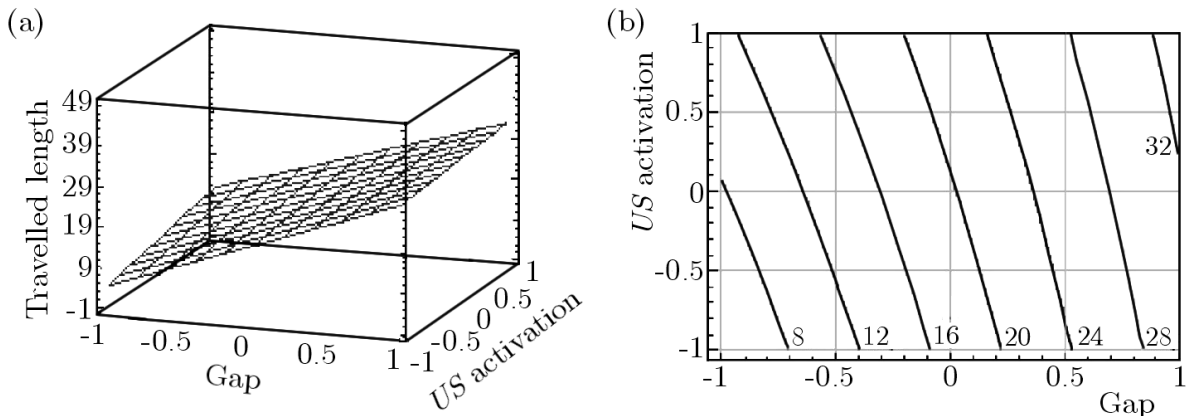

Fig. 15. The influence of gap an $U S$ activation 
$i_{\min }=0.5 \mathrm{~mm}$. Any increase of the flowing gap, even by $0.1 \mathrm{~mm}$, can decide on the capacity of the melt to fill that area and may dramatically affect the quality of the injected product.

Also the temperature $T$, shown in the Pareto chart (Fig. 7), is the second most important factor influencing the value of the objective function $L$.

Note that the ordering of the gap and the temperature in the first two positions is not affected by including the ultrasonic activation in the study. This situation shows no major interactions of the combined the $i-U S$ or $T$-US, excluding the possibility of spectacular effects from the ultrasonic activation.

However, the sets of factorial experiments $2^{4}$ in which the nozzle is ultrasonically activated designate the $U S$ asthe third influencing factor after the contribution that it has to increase the flow path.

Moreover, comparing the Pareto chart, one can conclude that the ultrasonic activation is more important for the quality of the filling than the injection pressure (exceeding the influence of the pressure in the Pareto charts) that conventionally has an outstanding influence on the length travelled by the melt.

This situation is a solid argument for the implementation of the industrial ultrasonic activation in injection moldings.

\section{Acknowledgment}

This paper has been supported by the Sectoral Operational Programme Human Resources Development POSDRU/159/1.5/S/137516 financed from the European Social Fund and by the Romanian Government.

\section{References}

1. Adam A., Cosma C., Dume A.I., Jadaneantu S., Pop A., 2013, Integration of CAD CAM techniques in the development of an injection mould for automotive parts, Proceedings of AMS 2013 International Conference, Timisoara, Romania, 25-27

2. Attia U.M., Marson S., Alcock J.R., 2009 Micro-injection moulding of polymer microfluidic devices, Microfluid Nanofluid, 7, 1-28

3. Aufiero R., 2005, The effect of process conditions on part quality in microinjection molding, ANTEC: Proceedings of Annual Technical Conference, Boston, MA, 36-40

4. Baltes L., Tierean M., 2009, Influence of the part shape on the polymer flow inside mould and overall strength, Annals of DAAM for 2009, Proceedings of the 20th International DAAM Symposium, 20, 1, 1107-1108, ISSN: 1726-9679

5. Bariani P.F., Salvador M., Lucchetta G., 2007, Development of a test method for the rheological characterization of polymers under the injection molding process conditions, Journal of Materials Processing Technology, 191, 1/3, 119-122

6. Chang D.H., 2007, Rheology and Processing of Polymeric Materials, Vol. 2, Polymer Processing, Oxford University Press Inc., New York, www.oup.com, ISBN: 978-0-19-518783-0

7. Eriksson L., Johansson N., Kettaneh-Wold N., Wikstrom C., Wold S., 2008, Design of Experiments: Principles and Applications, 3rd ed., Umetrics, Umeå

8. Iclanzan T., Serban I., Rotar D., Tut V., 2010, Ultrasonic activation, a possible alternative application in the microinjection molding, International Journal of Material Forming, 3, suppl. 1, $547-550$

9. Iclanzan T., Stan D., Abadie M., 2008, A possible new ultrasonic thermo-pellicular effect and applications, International Journal of Material Forming, 743-746, doi: 10.1007/s12289-008-0282-y 
10. Jung W.-C., Heo Y.-M., Shin K.-H., Yoon G.-S., Chang S.-H,, 2007, An experimatal study on micro injection paramaters, ANTEC: Proceedings of Annual Technical Conference, Cincinnati, $\mathrm{OH}, 638-642$

11. Malloy R., 1994, Plastic Part Design for Injection Molding, Carl Hanser Verlag, Munchen-New York

12. Mönkkönen K., Hietala J., PäÄkkönen P., PÄÄKkÖnen E.J., Kaikuranta T., Pakkanen T.T., JÄÄSKELÄINEN T., 2002, Replication of sub-micron features using amorphous thermoplastics, Polymer Engineering and Science, 42, 1600-1608

13. Patent No. RO118576 B, 2003, Ultrasonic activated mould (in Romanian)

14. Pirskanen J., Immonen J., Kalima V., Pietarinen J., Sittonen S., Kuittinen M., Mönkkönen K., Pakkanen T., Suvanto M., P̈̈̈̈Kkönen E.J., 2005, Replication of submicrometre features using microsystems technology, Plastics Rubber and Composites, 34, 222-226

15. Stan D., 1999, Activation ultrasonique des thermo-plastiques lors de la mise en oeuvre par injection et extrusion, PhD Thesis, Univ. Montpellier, France

16. Sîrbu A.N., 2009, Theoretical and experimental research on the ultrasonic activation effect on the molten polymers rheology, PhD Thesis, Politehnica University of Timisoara

17. Sîrbu N.A., IClĂNZAN T., OANCĂ O., 2008, Conception, design and realization of the ultrasonic assembly for flow activation devices of the polymeric media, Symposium of the Institute of Solid Mechanics, SISOM, Symposium of Acoustics, Bucharest

18. STAN D., 1999, The ultrasonic activation of the thermo-plastics in forming processes by injection and extrusion (in French), PhD Thesis, 1999, USTL Montpellier 2, France, www.sudoc.fr/06769939, accessed: 20 febr. 2015

19. Stan D., IClanzan T., Abadie M., 2000, The surface effect in the case of the ultrasonic activation of the visco-ellastically pressurized media (in French), Synthetic Polymer Journal, VII, 84-93

20. WimberGer-FriedL R., 2000, Injection molding of sub- $\mu$ m grating optical elements, Journal of Injection Molding Technology, 4, 78-83

21. Zhao J., Mayes R., Chen G., Xie H., Chan P., 2003, Effects of process parameters on the micro molding process, Polymer Engineering and Science, 43, 1542-1554 